\title{
RETRACTED ARTICLE: Application of nano-baskets in polymer inclusion membranes
}

\author{
Bahram Mokhtari · Kobra Pourabdollah
}

Received: 23 November 2012/ Accepted: 10 April 2013/Published online: 24 April 2013

(C) Springer Science+Business Media Dordrecht 2013

This article has been retracted at the request of the Publisher and Editors-in-Chief due a violation of Springer's Publishing Principles. The entire article 10.1007/s10847-013-0320-3 was found to be completely identical (with the exception of the title) to an unpublished article that was under review in another journal.

B. Mokhtari · K. Pourabdollah ( $\square)$

Razi Chemistry Research Center (RCRC), Islamic Azad

University, Shahreza Branch, Shahreza, Iran

e-mail: pourabdollah@iaush.ac.ir 